\title{
Authors' reply to Smith, Forsyth, Coffey and Prendergast, and Soskolne
}

\author{
Fiona Godlee editor in chief, on behalf of Mabel Chew, Catherine Brizzell, and Kamran Abbasi
}

The BMJ, London WC1H 9JR, UK

Thank you for these responses.

There seems to be some confusion about the extent of The BMJ's new policy as set out in our recent editorial. ${ }^{1}$ The policy applies only to editorials and clinical educational articles designed to guide patient care and does not extend to other types of article published in The BMJ. Moreover it precludes only those authors with a relevant commercial interest-one that relates directly to the topic of the article. Authors with relevant ties to commercial companies will still be welcome to write articles that are not editorials or clinical education articles for the journal. They may also be invited to write clinical education articles if their commercial interests have nothing to do with the article's topic. In answer to Richard Smith, ${ }^{2}$ GPs will still be invited to write articles on clinical care, and if Smith happened to be an expert on vaccines, the fact that he is also chair of Patients Know Best (a commercial company that provides software for patients to manage their own health data) would not preclude him from writing an editorial or review article on a new vaccine for us. He might also write non-editorial opinion pieces on the rights and wrongs of access to data, with full declaration of his interests. ${ }^{2}$ But we would probably not invite him to write an editorial on how best to give patients access to their data, as readers might have difficulty in perceiving such a piece as truly independent of his affiliations. And yes this is about perception of bias as much as reality. The research on perceived bias is, as Forsyth points out, ${ }^{3}$ limited. But there is longstanding evidence of actual commercial bias in reviews and commentaries. ${ }^{45} \mathrm{We}$ greatly value our authors but we make no apology for prioritising the needs of our readers and their patients. Authors with industry ties have many other outlets if they wish to publish clinical educational articles on topics related to those ties.

In his full response online, Smith raises concerns about academic prejudice as a potent source of bias, which our policy does not address. And Coffey and Prendergast make a similar point - that authors may take controversial rules in order to get published. ${ }^{6}$ We agree that this is a problem. Our defences against it, on behalf of readers, are pre-publication peer review to ensure as far as possible that articles are properly evidence based, and the fact that The BMJ's authors are accountable to readers through our rapid responses should they fail to keep their prejudices in check.

Coffey and Prendergast also ask why the NHS should pay for what may become a marketing opportunity for manufacturers. I would answer that the NHS should be funding, and in this case probably is funding, good independent science regardless of the results.

Yes, some authors will not properly declare their interests, as the New England Journal of Medicine found when trying to enforce a similar policy in the 1990s. But we are using rigorous processes $^{1}$ that we hope will make this less likely. We hope too that authors will choose complete honesty up front rather than risk post-publication embarrassment in the journal's rapid responses. This is one of several aspects of this experiment that we will audit and report back on in the journal.

As for our own conflicts of interest, The $B M J$ sits within a commercial company, but the journal's editors do not own shares or have other interests in industry as defined in the editorial. The BMJ gets some of its revenue from pharmaceutical advertising and sponsorship but as with all good journals there is strict purdah between the editorial and commercial teams.

Finally, Forsyth chides us for taking the law into our own hands. ${ }^{3}$ To my mind, this is a journal editor's job, within reason: to set policies that in small ways push and prod the worlds of clinical and academic medicine towards what we judge will be a better future. $^{7}$ And yes, I hope this will eventually mean no more promotional pens.

\section{Competing interests: None declared.}

Chew M, Brizzell C, Abbasi K, Godlee F. Medical journals and industry ties. $B M$ 2014;349:g7197. (28 November)

Smith R. Reasons to be cautious about competing interests. BMJ 2015;350:g7754.

3 Forsyth $\mathrm{S}$. The BMJ should not take the law into its own hands on competing interests. BMJ 2015;350:g7766.

4 Stelfox HT, Chua G, O'Rourke K, Detsky AS. Conflict of interest in the debate over calcium-channel antagonists. N Engl J Med 1998;338:101-6. 
Barnes DE, Bero LA. Why review articles on the health effects of passive smoking reach different conclusions. JAMA 1998;279:1566-70.

6 Coffey S, Prendergast BD. Public healthcare systems should not pay for private profit. BMJ 2015;350:g7774.

7 Soskolne CL. Competing interests in epidemiology. BMJ 2015;350:g7744.
Cite this as: BMJ 2015;350:h42

๑ BMJ Publishing Group Ltd 2015 